\title{
A serum microRNA signature as a prognostic factor for patients with advanced NSCLC and its association with tissue microRNA expression profiles
}

\author{
JING GUO ${ }^{1,2}$, RUI MENG ${ }^{1}$, ZHONGYUAN YIN ${ }^{1}$, PENGCHENG LI $^{1}$, RUI ZHOU ${ }^{1}$, \\ SHENG ZHANG ${ }^{1}$, XIAORONG DONG ${ }^{1}$, LI LIU $^{1}$ and GANG WU ${ }^{1}$ \\ ${ }^{1}$ Cancer Center, Union Hospital, Tongji Medical College, Huazhong University of Science and Technology, \\ Wuhan, Hubei 430022; ${ }^{2}$ Department of Oncology, The Affiliated Hospital of Qingdao University, \\ Qingdao, Shandong 266003, P.R. China
}

Received May 4, 2015; Accepted March 14, 2016

DOI: $10.3892 / \mathrm{mmr} .2016 .5114$

\begin{abstract}
The aim of the present study was to detect microRNA (miRNA) signatures in advanced non-small cell lung cancer (NSCLC), and to study the association between miRNA expression levels in serum and tissue. A cohort of patients who had previously been diagnosed with advanced NSCLC was enrolled in the present study. miRNAs associated with prognosis, which had previously been detected in early stage NSCLC samples, were measured in the serum of the patient groups using a cross-validation method. In addition, serum miRNAs associated with progression-free survival (PFS) were detected in paired fresh tissue samples, in order to analyze the correlation between serum and tissue expression levels. A risk-score analysis was used to develop a four-miRNA signature to predict PFS. miR-1, miR-30d, miR-221 and miR-486 were identified as having a significant correlation with PFS in advanced NSCLC. miR-221 and miR-486 exhibited significant positive correlations between serum and tissue expression. Furthermore, overexpression of miR-221 and reduced expression of miR-486 increased cell proliferation, migration and invasion in vitro. In conclusion, the miRNA signature identified in the present study may be considered an independent prognostic factor of PFS in advanced NSCLC. In addition, the expression levels of miR-221 and miR-486 were significantly correlated between serum and tissue. miR-221 was identified as an oncogenic risk factor, whereas miR-486 exerted protective effects against cancer cell proliferation, migration and invasion.
\end{abstract}

Correspondence to: Professor Gang Wu, Cancer Center, Union Hospital, Tongji Medical College, Huazhong University of Science and Technology, 1277 JieFang Avenue, Wuhan, Hubei 430022, P.R. China

E-mail: xhzlwg@163.com

Key words: microRNAs, non-small cell lung cancer, biomarker, prognosis

\section{Introduction}

Lung cancer is a leading cause of cancer-associated mortality worldwide, predominantly from cases of non-small cell lung cancer (NSCLC) (1). The prognosis for lung cancer is poor, particularly in the advanced stages $(2,3)$. To select the most effective therapeutic strategy, prognostic assessment is required (4). Although there are diverse clinical indicators for prognostic evaluation, patients with cancer who exhibit similar clinical features nonetheless may experience markedly different clinical outcomes. With the recent development of gene profiling techniques, including microRNA (miRNA) microarrays and reverse transcription-quantitative polymerase chain reaction (RT-qPCR), novel molecular biomarkers may be used as prognostic factors in addition to traditional clinical characteristics (5-7).

miRNAs comprise a class of noncoding small RNAs that participate in various biological processes. Usually, miRNAs function at the post-transcriptional level and regulate hundreds of target mRNAs, thus serving various roles in biological functions, including tumorigenesis and cancer progression (8). miRNA expression profiles have been identified in various tissues and diseases. Furthermore, miRNAs have been identified as biomarkers for the diagnosis, treatment and prognosis of various diseases (9-13).

A miRNA signature containing five miRNAs (miR-221, let-7a, miR-137, miR-372 and miR-182) was previously reported to be associated with overall survival (OS) and progression-free survival (PFS) in patients with early stage NSCLC, following examination of frozen specimens subsequent to surgical resection (14). Another miRNA signature comprising four miRNAs (miR-486, miR-30d, miR-1 and miR-499) in serum has been reported to be associated with outcome in early stage NSCLC (15). However, whether the above miRNAs can predict the clinical outcome of advanced stage NSCLC remains unknown. In addition, the correlation between tissue and serum miRNA expression remains to be elucidated.

To investigate these problems, the present study detected the aforementioned miRNAs in serum, in order to analyze their association with survival. Furthermore, the serum miRNAs 
associated with PFS were detected in paired tissue samples, to determine the expression correlation. Finally, the present study attempted to verify the functions of relevant miRNAs in vitro.

\section{Materials and methods}

Patient enrollment and sample processing. The present study was approved by the Ethics Committee of the Tongji Medical Department, Huazhong University of Science and Technology (Wuhan, China). All participants provided written informed consent to participate in the present study, and the ethics committee approved this consent procedure. Serum miRNAs were detected from 68 consecutive patients enrolled between December 2012 and May 2013 at the Cancer Center, Union Hospital, Tongji Medical College, Huazhong University of Science and Technology. The final follow-up was in December 2013. The median time of follow-up was 256 days. All of the patients were first pathologically confirmed to suffer from locally advanced or metastatic NSCLC, and developed progressive disease during follow-up. Due to the high censor rate, OS statistics were not calculated. Fresh tissue specimens were obtained from 24 patients using computed tomography-guided percutaneous lung biopsy, and were paired with the corresponding patient's serum, in order to analyze the correlation between the two sample types. Following admission into hospital, a $5 \mathrm{ml}$ peripheral blood sample was collected into a gold-top serum-separating tube. The lung cancer subtypes were authenticated by the Pathology Department, Union Hospital, Tongji Medical College, Huazhong University of Science and Technology, according to the World Health Organization classification (16). The evaluation after treatment was performed according to the Response Evaluation Criteria in Solid Tumors Version 1.1 (17). The objective tumor response was evaluated every 6-8 weeks. Clinical data were retrieved from the electronic medical records database of the Cancer Center, Union Hospital, Tongji Medical College, Huazhong University of Science and Technology.

miRNA isolation and quantification. The serum specimens were incubated at room temperature for $30 \mathrm{~min}-2 \mathrm{~h}$ and were centrifuged at $12,000 \times \mathrm{g}$ for $15 \mathrm{~min}$ at $4^{\circ} \mathrm{C}$. Subsequently, the samples were dispensed into Eppendorf tubes and were stored at $-80^{\circ} \mathrm{C}$ until further use. Serum total RNA was isolated using the mirVana ${ }^{\mathrm{TM}}$ PARIS ${ }^{\mathrm{TM}}$ kit (Ambion; Thermo Fisher Scientific, Inc., Waltham, MA, USA). Based on reports that there are no favorable stably expressed genes in serum, a synthetic Caenorhabditis elegans miRNA (cel-miR-39; 5'-UCACCG GGUGUAAAUCAGCUUG-3'; Guangzhou RiboBio Co., Ltd., Guangzhou, China) was selected as a control gene, of which $25 \mathrm{fmol}$ was added after the addition of denaturing solution to each sample in the serum miRNA isolation procedure $(18,19)$.

Fresh tissue specimens were immediately transferred into RNAlater RNA Stabilization Reagent (Qiagen, Inc., Valencia, CA, USA) after being obtained and were stored at $-80^{\circ} \mathrm{C}$. The tissue samples were homogenized prior to RNA extraction. The E.Z.N.A ${ }^{\circledR}$. Total RNA kit II (Omega Bio-tek, Norcross, GA, USA) was used to extract total RNA from the tissue, and small nuclear U6 RNA was used for normalization.

RT was performed on total RNA using a stem-loop RT primer (Applied Biosystems; Thermo Fisher Scientific, Inc.;
Table I), and the TaqMan microRNA Reverse Transcription kit (Applied Biosystems; Thermo Fisher Scientific, Inc.). The total reaction volume $(15 \mu \mathrm{l})$ was incubated in a TProfessional Basic Thermocycler (Biometra GmbH, Göttingen, Germany). qPCR was performed using the SYBR ${ }^{\circledR}$ Select Master Mix (Applied Biosystems; Thermo Fisher Scientific, Inc.) and the Step One Plus system (Applied Biosystems; Thermo Fisher Scientific, Inc.). A volume of $2 \mu \mathrm{l}$ diluted reverse transcription product was mixed with $10 \mu \mathrm{l}$ SYBR Select Master Mix (2X; Applied Biosystems; Thermo Fisher Scientific, Inc.), $0.8 \mu 1$ forward and reverse primers (Applied Biosystems; Thermo Fisher Scientific, Inc.) and $6.4 \mu \mathrm{l}$ nuclease-free water to a final volume of $20 \mu \mathrm{l}$. All reactions were performed in triplicate under the following thermal cycling conditions: $50^{\circ} \mathrm{C}$ For 2 min and $95^{\circ} \mathrm{C}$ for $2 \mathrm{~min}$, followed by 40 cycles at $95^{\circ} \mathrm{C}$ for $3 \mathrm{sec}$ and $60^{\circ} \mathrm{C}$ for $30 \mathrm{sec}$.

Cell culture and transfection. The H358 and PC9 human lung cancer cell lines were obtained from the Laboratory of the Cancer Center, Union Hospital, Tongji Medical College, Huazhong University of Science and Technology. The cells were cultured in RPMI 1640 medium (Hyclone; GE Healthcare Life Sciences, Logan, UT, USA) supplemented with $10 \%$ fetal bovine serum (FBS; Gibco; Thermo Fisher Scientific, Inc.) at $37^{\circ} \mathrm{C}$ in an atmosphere containing $5 \% \mathrm{CO}_{2}$.

The hsa-mir-221-3p mimic, hsa-mir-221-3p inhibitor, hsa-mir-486-5p mimic and hsa-mir-486-5p inhibitor were purchased from Guangzhou RiboBio Co., Ltd.. Cells were plated to $50 \%$ confluence in each well, and were transfected with $50 \mathrm{nM}$ mimic or mimic negative control (mimic NC), or with $100 \mathrm{nM}$ inhibitor or inhibitor NC using Lipofectamine 2000 (Invitrogen; Thermo Fisher Scientific, Inc.) in Opti-MEM (Gibco; Thermo Fisher Scientific, Inc.), according to the manufacturer's protocol.

MTT assay. The viable cell numbers were measured using the 3-(4,5-dimethylthiazol-2-yl)-2,5-diphenyltetrazolium bromide (MTT) assay (Sigma-Aldrich, St. Louis, MO, USA). The H358 and PC9 cells were seeded at a density of $5 \times 10^{3}$ cells/well in 96-well plates, and were transfected with miR-221 mimic, miR-221 inhibitor, miR-486 mimic, miR-486 inhibitor, mimic $\mathrm{NC}$ or inhibitor NC. The cells were incubated for 24,48 or $72 \mathrm{~h}$ post-transfection. The MTT assay was conducted according to the manufacturer's protocol. A total of $20 \mu \mathrm{l}$ MTT $(5 \mathrm{mg} / \mathrm{ml})$ was added to each well, and the plates were incubated for $4 \mathrm{~h}$ at $37^{\circ} \mathrm{C}$ in an atmosphere containing $5 \% \mathrm{CO}_{2}$. Subsequently, the supernatant was discarded, and $200 \mu 1$ dimethyl sulfoxide was added to each well, in order to dissolve the formazan. The optical density was evaluated by measuring the absorbance of each well at $570 \mathrm{~nm}$ using a spectrophotometer (M450; Bio-Rad Laboratories, Inc., Hercules, CA, USA). All experiments were performed in triplicate.

Wound healing assay. The H358 and PC9 cells $\left(\sim 5 \times 10^{5}\right)$ suspended in $2 \mathrm{ml}$ complete medium (Hyclone; GE Healthcare Life Sciences) were seeded into 6-well plates, and cell confluence reached $\sim 80 \% 24$ h post-transfection. A scratch was created by drawing a straight line in each well using a $200-\mu 1$ pipette tip. Any debris was washed off using phosphate-buffered saline. The 6-well plates were then incubated in serum-free medium 
Table I. Reverse transcription-quantitative polymerase chain reaction primers.

\begin{tabular}{|c|c|}
\hline Gene & Primer sequence $\left(5^{\prime}-3^{\prime}\right)$ \\
\hline hsa-miR-1 & $\begin{array}{l}\text { RT GTCGTATCCAGTGCAGGGTCCGAGGTATTCGCACTGGATAC } \\
\text { F GACATACATGGCAGGTGGAATGTAAAGAAGT } \\
\text { R CAGTGCAGGGTCCGAGGTAT }\end{array}$ \\
\hline hsa-let-7a-5p & $\begin{array}{l}\text { RT GTCGTATCCAGTGCAGGGTCCGAGGTATTCGCACTGGATAC } \\
\text { F GACAACTATGGTCGTGAGGTAGTAGGTTGTA } \\
\text { R CAGTGCAGGGTCCGAGGTAT }\end{array}$ \\
\hline hsa-miR-30d-5p & $\begin{array}{l}\text { RT GTCGTATCCAGTGCAGGGTCCGAGGTATTCGCACTGGATAC } \\
\text { F GACCTTCCACCTGTGTAAACATCCCCGAC } \\
\text { R CAGTGCAGGGTCCGAGGTAT }\end{array}$ \\
\hline hsa-miR-221-3p & $\begin{array}{l}\text { RT GTCGTATCCAGTGCAGGGTCCGAGGTATTCGCACTGGATAC } \\
\text { F GACGAAACCGGGAGCTACATTGTCTGCTGG } \\
\text { R CAGTGCAGGGTCCGAGGTAT }\end{array}$ \\
\hline hsa-miR-499a-5p & $\begin{array}{l}\text { RT GTCGTATCCAGTGCAGGGTCCGAGGTATTCGCACTGGATAC } \\
\text { F GACAAACATCGGTGCTTAAGACTTGCAGTGA } \\
\text { R CAGTGCAGGGTCCGAGGTAT }\end{array}$ \\
\hline hsa-miR-486-5p & $\begin{array}{l}\text { RT GTCGTATCCAGTGCAGGGTCCGAGGTATTCGCACTGGATAC } \\
\text { F GACCTCGGGCGTCCTGTACTGAGCTGCC } \\
\text { R GTGCAGGGTCCGAGGT }\end{array}$ \\
\hline cel-miR-39 & $\begin{array}{l}\text { RT GTCGTATCCAGTGCAGGGTCCGAGGTATTCGCACTGGATAC } \\
\text { F GACCAAGCTGCGGTCACCGGGTGTAAATC } \\
\text { R GTGCAGGGTCCGAGGT }\end{array}$ \\
\hline U6 & $\begin{array}{l}\text { RT CGAATTTGCGTGTCATCCT } \\
\text { F CTCGCTTCGGCAGCACATA } \\
\text { R CGAATTTGCGTGTCATCCT }\end{array}$ \\
\hline
\end{tabular}

miR, microRNA; RT, reverse transcription; F, forward; R, reverse.

for $24 \mathrm{~h}$, and subsequently three fields were randomly picked from each scratch wound and analyzed at 200x magnification (CKX41; Olympus Corporation). The experiments were performed in triplicate.

Transwell migration and invasion assay. The $\mathrm{H} 358$ and PC9 cells were resuspended in RPMI 1640 medium $24 \mathrm{~h}$ post-transfection. For the transwell migration assay, $4 \times 10^{4}$ seeded H358 cells $(200 \mu 1)$ or $2 \times 10^{4}$ seeded PC 9 cells $(200 \mu \mathrm{l})$ were plated in the top chamber with the non-coated membrane (24-well insert; pore size, $8 \mu \mathrm{m}$; BD Biosciences, Franklin Lakes, NJ, USA). For the invasion assay, cells were plated in the top chamber with extracellular matrix gel (Sigma-Aldrich)-coated membranes (24-well insert; pore size, $8 \mu \mathrm{m}$; BD Biosciences). The lower regions were filled with $800 \mu \mathrm{l}$ RPMI 1640 containing 20\% FBS as a chemoattractant. Following a $24 \mathrm{~h}$ incubation, the cells on the upper surface of the membrane were removed with a cotton swab. The cells on the lower surface of the membrane were fixed with methyl alcohol for $20 \mathrm{~min}$, and were stained with $0.1 \%$ crystal violet for $15 \mathrm{~min}$. The number of invading cells was counted in three randomly selected visual fields using a microscope (CKX41; Olympus Corporation, Tokyo, Japan) at 200x magnification. The experiments were performed in triplicate.
Statistical analysis. The RT-qPCR data were analyzed using the comparative quantification cycle $(\mathrm{Cq})$ method. Standard curves were created prior to analysis of the specimens. The correlation coefficients were $>0.995$, and the amplification efficiencies were in the range of $1 \pm 20 \%$. The expression level of each miRNA was classified according to the median relative quantification measured by $2^{-\Delta \Delta \mathrm{Cq}}\left(\Delta \mathrm{Cq}=\mathrm{Cq}_{\text {miRNA }}\right.$ expression $-\mathrm{Cq}_{\text {control expression }}$ ) (20). During the pre-experiment, three (miR-137, miR-182, and miR-372) of the nine miRNAs exhibited unstable or undetermined expression in serum; therefore, these three miRNAs were not analyzed.

A cross-validation method was used to investigate the value of the miRNAs for predicting PFS. The 68 serum specimens were randomly assigned to a training set $(n=34$; used to establish a model) or a testing set ( $n=34$; used to verify the model). In the training set, a risk score formula was established based on a linear combination of the miRNA expression level weighted by the regression coefficient derived from a univariate Cox regression analysis. Student's t-test and Chi-squared test were used to evaluate the differences in clinical characteristics. The risk score was calculated as follows: Risk score $=(-0.918 \times$ miR-1 expression level $)+(1.336$ x miR-30d expression level $)+(0.864 \times$ miR-221 expression level $)+(-0.712 \times$ miR-486 expression level). Patients with higher risk scores were expected to have shorter PFS. 
Table II. Univariate Cox regression analysis of the training set.

Univariate Cox regression analysis

\begin{tabular}{lclll}
\cline { 2 - 5 } miRNA & $\beta$ & HR & $95 \%$ CI & P \\
\hline hsa-miR-1 & -0.918 & 0.4 & $0.197-0.809$ & 0.011 \\
hsa-let-7a-5p & 0.345 & 1.412 & $0.698-2.860$ & 0.337 \\
hsa-miR-30d-5p & 1.338 & 3.812 & $1.655-8.781$ & 0.002 \\
hsa-miR-221-3p & 0.846 & 2.331 & $1.122-4.846$ & 0.023 \\
hsa-miR-499a-5p & 0.242 & 1.274 & $0.633-2.565$ & 0.498 \\
hsa-miR-486-5p & -0.712 & 0.491 & $0.242-0.997$ & 0.049 \\
\hline
\end{tabular}

miR, microRNA; HR, hazard ratio; CI, confidence interval.

According to the risk score, a receiver operating characteristics analysis was used to determine a cutoff point (0.518) with an area under the curve of 0.877 (the sensitivity was 0.941 , and the specificity was 0.706$)$. Hence, the patients in the training set were divided into a high-risk group and a low-risk group. The same statistical models were applied to the testing set and the combined set. Survival differences between the high-risk and low-risk groups were estimated using a Kaplan-Meier analysis and 2-sided log-rank tests. A Cox proportional hazards regression analysis was performed to assess the independent contributions of the risk score and clinicopathological characteristics to survival prediction.

To analyze the correlation between serum and tissue miRNAs, the four survival-associated miRNAs were detected in 24 fresh tissue samples paired with 24 serum samples. In the pre-experiment, the expression of miR-1 was undetermined; therefore, three miRNAs were ultimately tested. A Pearson analysis was used to test the correlation.

All statistical analyses were performed using SPSS version 21.0 (IBM SPSS, Armonk, NY, USA). All experiments were performed in triplicate. All tests were two-tailed, and $\mathrm{P}<0.05$ was considered to indicate a statistically significant difference.

\section{Results}

Detection of serum miRNAs in the training set. Six miRNAs were detected in the training set serum specimens $(n=34)$, and a Cox proportional hazards regression was applied to each of the six miRNAs to determine the PFS-associated miRNA signature. Four of the miRNAs were identified to be associated with PFS. Subsequently, a signature was constructed using the risk score method. As shown in Table II, two miRNAs (miR-1 and miR-486) were revealed to be protective, whereas the other two (miR-30d and miR-221) were identified as risk factors (Table II).

Four-miRNA signature and patient survival in the training set. The risk score formula was used to calculate the risk score in the training set, and to divide the set into a high-risk group and a low-risk group according to a cutoff value. Patients in the high-risk group had a shorter PFS compared with those in the low-risk group: 85 days vs. 228 days ( $\mathrm{P}<0.001$; Fig. $1 \mathrm{~A}$ and $\mathrm{B})$.
The patients in the high-risk and low-risk groups exhibited similar clinical characteristics (Table III).

Validation of the four-miRNA signature for survival prediction in the testing and combined set. The same risk-score formula and cutoff value obtained from the training set were used to analyze the testing and combined sets. Following calculation of the risk score, the patients were classified into a high-risk group and a low-risk group. Similar findings were revealed in this analysis; the high-risk group had a shorter PFS compared with that of the low-risk group: 85 Days vs. 151 days in the testing set $(\mathrm{P}=0.029)$ and 85 days vs. 176 days $(\mathrm{P}<0.001)$ in the combined set (Figs. 1C and D, and 2). The low-risk group exhibited high expression levels of protective miRs and low expression of risk-related miRs, and the high-risk group exhibited low expression levels of protective miRs and high expression of risk-related miRs (Figs. 1C and D, and 2).

To investigate whether this serum four-miRNA signature is an independent predictor of PFS, a multivariate Cox regression analysis was performed. The results indicate that the miRNA signature $(\mathrm{P}<0.001)$ and smoking status $(\mathrm{P}=0.037)$ were significantly associated with PFS (Table IV).

Correlation between serum and tissue miRNAs. The four miRNAs were subsequently detected in the corresponding fresh tissue specimens; however, miR-1 was expression was undetermined. A Pearson correlation analysis was performed to analyze the relative quantification of the serum and tissue miRNAs. Two of the three miRNAs exhibited correlations between the serum and tissue levels. The correlation coefficients for miR-30d, miR-221 and miR-486 were 0.383 $(\mathrm{P}=0.065), 0.673(\mathrm{P}=0.001)$ and $0.685(\mathrm{P}<0.001)$, respectively (Fig. 3A-C).

Upregulation of miR-221 or downregulation of miR-486 promotes cell proliferation, migration and invasion in lung cancer cells. To study the biological roles of miR-221 and miR-486, transiently transfected H358 and PC9 cell lines were constructed. miR-221 mimic and inhibitor, miR-486 mimic and inhibitor, and mimic NC and inhibitor NC were transfected into the H358 and PC9 cell lines (Fig. 4A).

Using the MTT assay, the effects of miR-221 and miR-486 on the lung cancer cell lines were evaluated. Upregulation 
Table III. Clinical characteristics in the training set, testing set and combined set.

\begin{tabular}{|c|c|c|c|}
\hline Characteristic & High risk & Low risk & $\mathrm{P}$ \\
\hline Training set & 21 & 13 & \\
\hline Age & $57.81 \pm 7.369$ & $54.69 \pm 9.187$ & $0.283^{\mathrm{a}}$ \\
\hline \multicolumn{4}{|l|}{ Gender } \\
\hline Male & 17 & 8 & \\
\hline Female & 4 & 5 & $0.254^{b}$ \\
\hline \multicolumn{4}{|l|}{ Smoking status } \\
\hline No & 11 & 8 & \\
\hline Yes & 10 & 5 & $0.728^{b}$ \\
\hline \multicolumn{4}{|l|}{ Pathology } \\
\hline Adenocarcinoma & 18 & 10 & \\
\hline Squamous carcinoma & 3 & 3 & $0.653^{b}$ \\
\hline \multicolumn{4}{|l|}{ Clinical stage } \\
\hline $\mathrm{IIIb}$ & 2 & 2 & \\
\hline IV & 19 & 11 & $0.627^{b}$ \\
\hline Testing set & 21 & 13 & \\
\hline Age & $60.19 \pm 10.186$ & $63.23 \pm 8.584$ & $0.377^{\mathrm{a}}$ \\
\hline \multicolumn{4}{|l|}{ Gender } \\
\hline Male & 14 & 8 & \\
\hline Female & 7 & 5 & $1.000^{\mathrm{b}}$ \\
\hline \multicolumn{4}{|l|}{ Smoking status } \\
\hline No & 10 & 5 & \\
\hline Yes & 11 & 8 & $0.728^{b}$ \\
\hline \multicolumn{4}{|l|}{ Pathology } \\
\hline Adenocarcinoma & 19 & 11 & \\
\hline Squamous carcinoma & 2 & 2 & $0.627^{b}$ \\
\hline \multicolumn{4}{|l|}{ Clinical stage } \\
\hline IIIb & 3 & 2 & \\
\hline IV & 18 & 11 & $1.000^{\mathrm{b}}$ \\
\hline Combined & 42 & 26 & \\
\hline Age & $59.00 \pm 8.859$ & $58.96 \pm 9.739$ & $0.987^{\mathrm{a}}$ \\
\hline \multicolumn{4}{|l|}{ Gender } \\
\hline Male & 31 & 16 & \\
\hline Female & 11 & 10 & $0.418^{b}$ \\
\hline \multicolumn{4}{|l|}{ Smoking status } \\
\hline No & 21 & 13 & \\
\hline Yes & 21 & 13 & $1.000^{\mathrm{b}}$ \\
\hline \multicolumn{4}{|l|}{ Pathology } \\
\hline Adenocarcinoma & 37 & 21 & \\
\hline Squamous carcinoma & 5 & 5 & $0.489^{\mathrm{b}}$ \\
\hline \multicolumn{4}{|l|}{ Clinical stage } \\
\hline IIIb & 5 & 4 & \\
\hline IV & 37 & 22 & $0.723^{b}$ \\
\hline
\end{tabular}

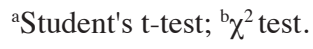

of miR-221 or downregulation of miR-486 promoted cell proliferation, whereas the reverse processes inhibited cell proliferation (Fig. 4B).
The effects of miR-221 and miR-486 on cell migration and invasion were also studied. Transfection with miR-221 mimic or miR-486 inhibitor significantly enhanced cell migration; 
Table IV. Cox regression analyses of the combined set.

\begin{tabular}{|c|c|c|c|c|c|c|}
\hline \multirow[b]{2}{*}{ Characteristic } & \multicolumn{3}{|c|}{ Univariate Cox regression analysis } & \multicolumn{3}{|c|}{ Multivariate Cox regression analysis } \\
\hline & HR & $95 \% \mathrm{CI}$ & $P$ & HR & $95 \%$ CI & $\mathrm{P}$ \\
\hline Age & 1.012 & $0.986-1.038$ & 0.378 & & & 0.913 \\
\hline Gender & 0.584 & $0.337-1.014$ & 0.054 & & & 0.264 \\
\hline Smoking status & 1.443 & $0.860-2.420$ & 0.165 & 1.760 & $1.033-2.996$ & 0.037 \\
\hline Pathology & 0.772 & $0.392-1.521$ & 0.454 & & & 0.321 \\
\hline Clinical stage & 1.061 & $0.519-2.172$ & 0.870 & & & 0.141 \\
\hline Risk score & 2.326 & $1.759-3.172$ & $<0.001$ & 2.545 & $1.859-3.484$ & $<0.001$ \\
\hline
\end{tabular}

HR, hazard ratio; CI, confidence interval.

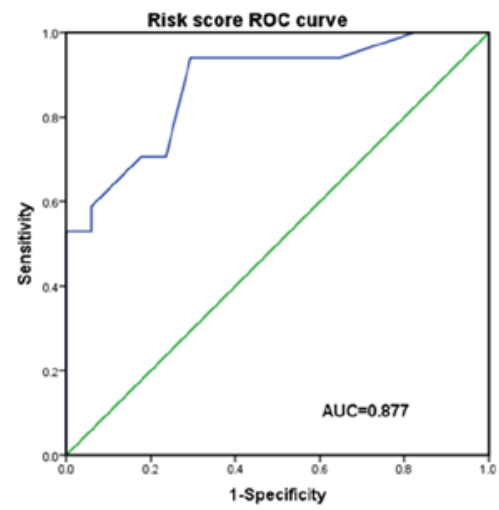

C

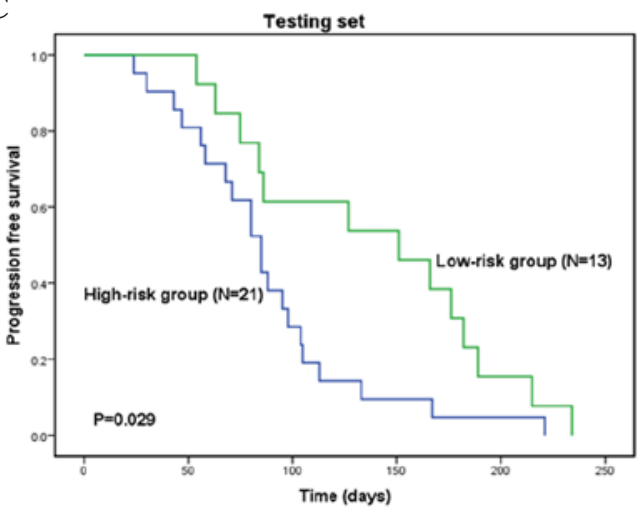

B

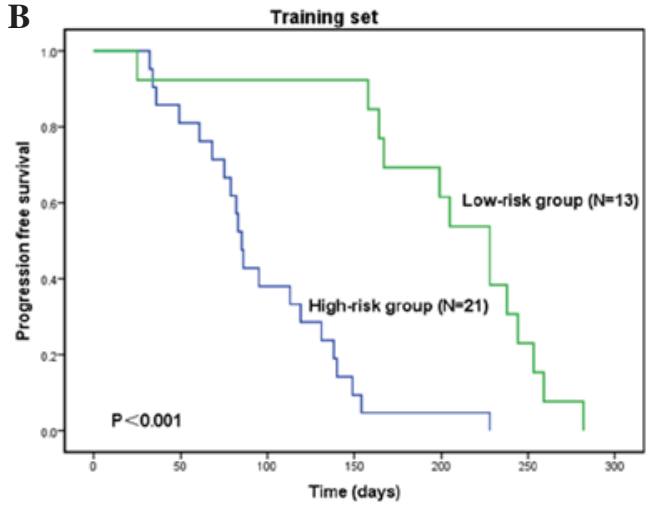

D

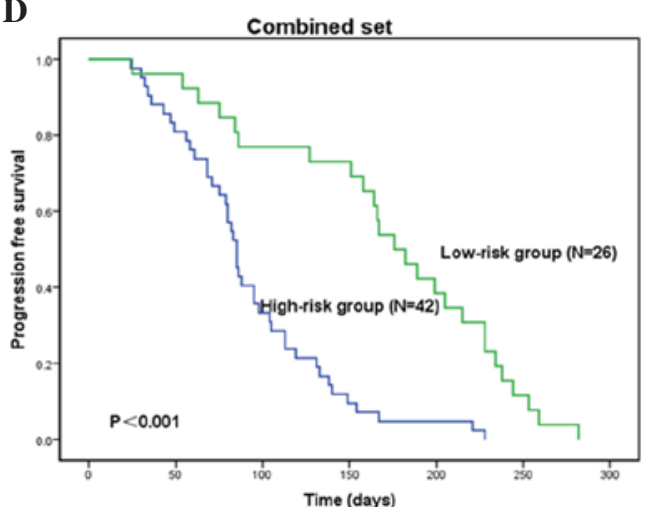

Figure 1. Receiver operating characteristic (ROC) curve and Kaplan-Meier analysis of serum specimens. Patients were stratified into a high-risk group and a low-risk group according to a risk score formula. (A) With a cutoff point of 0.518 , the risk score formula exhibited a higher diagnostic efficacy, with a sensitivity of 0.941 and a specificity of 0.706 . Kaplan-Meier analysis of the (B) training set, (C) testing set and (D) combined set indicated that the high-risk group had a shorter PFS compared with that of the low-risk group. AUC, area under curve.

however, transfection with miR-221 inhibitor or miR-486 mimic did not affect cell migration (Fig. 5A and B). Consistent with these findings, the results of a Matrigel invasion assay demonstrated that overexpression of miR-221 or knockdown of miR-486 strengthened the invasive capacity of the cells (Fig. 5C).

\section{Discussion}

Due to the lack of reliable biomarkers for the early detection and prognosis of malignancy, the identification of biomarkers is of great importance. The serum expression of miRNAs was initially described by Chim et al (21); subsequently, miRNAs have been demonstrated to tolerate degradation, freezing, thawing and extreme $\mathrm{pH}$ conditions $(22,23)$. In 2008, it was reported that miRNAs may be considered a novel class of cancer biomarkers $(22,24)$. At present, the use of miRNAs has been widely reported in cancer diagnosis, clinical characteristics, individualized treatment and prognosis $(8,9,25,26)$.

NSCLC is a heterogeneous disease. The current standard of treatment for patients with advanced or stage IV NSCLC is 4-6 cycles of chemotherapy, which is followed by maintenance 

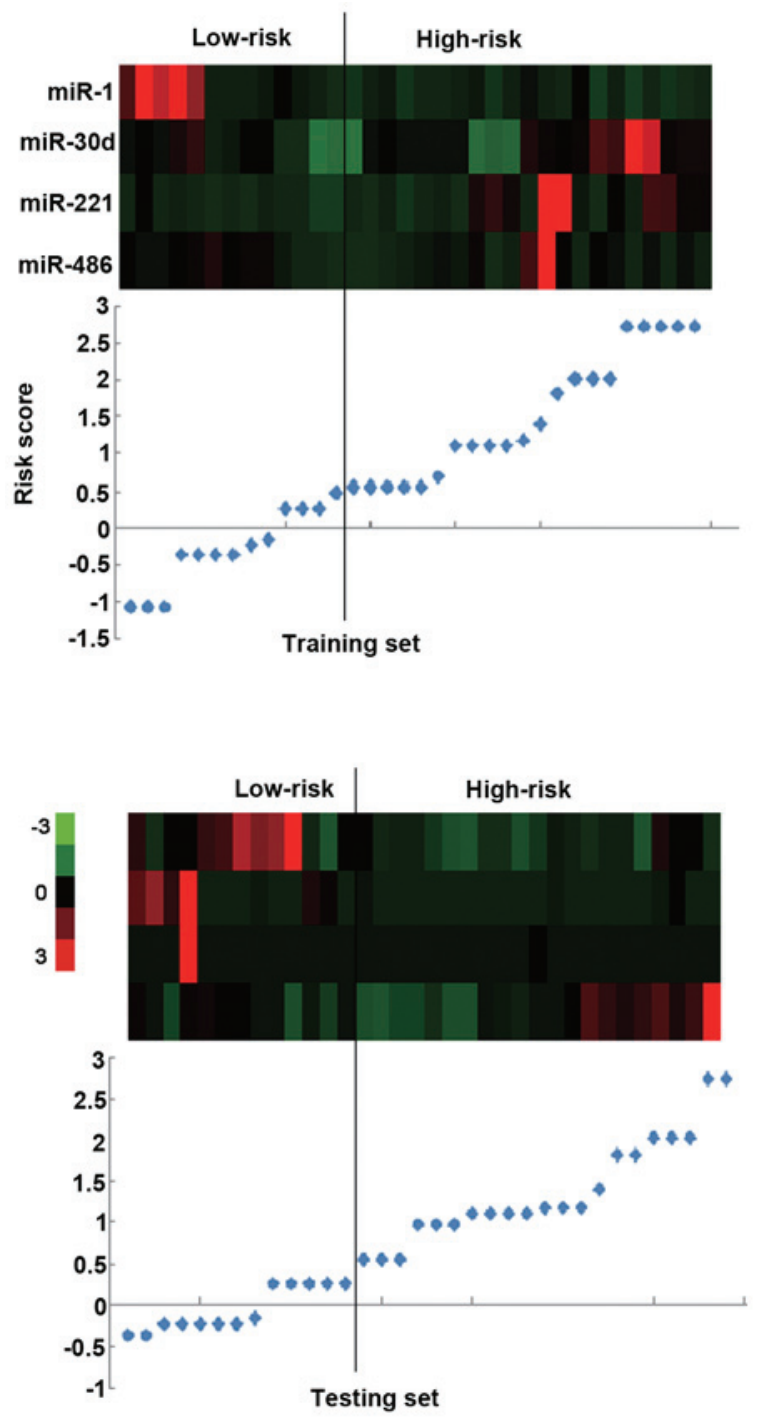

Figure 2. A cluster analysis was performed in the training set and testing set. The black line divides the patients into the high-risk and low-risk groups. The low-risk patients exhibited high expression levels of protective miRs and low expression of risk-related miRs, and vice versa. Red, high expression; green, low expression. miR, microRNA.

therapy in a subgroup of patients without progression. Analysis of the clinical characteristics of patients with lung cancer, including patient age, and the number, size and location of metastatic sites, may have reached the limit of its usefulness for predicting outcomes; therefore, molecular biomarkers may add value to this analysis. The ability to more accurately identify subgroups of patients may refine prognostic models and lead to more personalized lung cancer treatments. This advancement may help determine which groups of patients require more aggressive therapy, such as 6 cycles of chemotherapy plus maintenance therapy.

The present study reproducibly validated previously identified early stage NSCLC prognosis-associated miRNAs using an RT-qPCR analysis. These miRNAs were previously revealed to be associated with the PFS and OS of patients with early stage NSCLC. miR-137, miR-372, miR-182, miR-221 and let-7a were tested in quick-frozen tissue samples from surgery (14), and miR-486, miR-30d, miR-1 and miR-499 were tested in serum (15). All of the specimens were obtained from
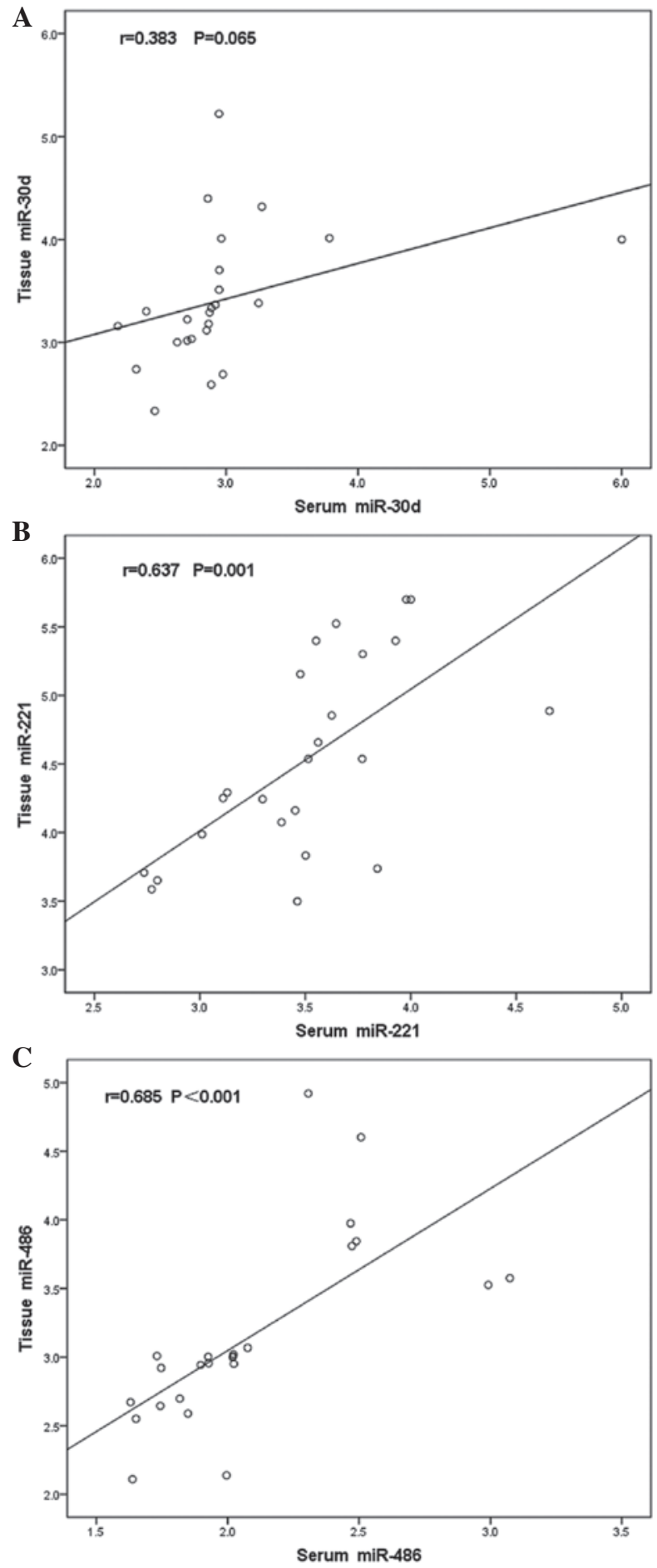

Figure 3. Pearson correlation analysis of (A) miR-30d, (B) miR-221 and (C) miR-486 levels between 24 paired tissue and serum specimens. Significant positive correlations were detected between the tissue and serum levels of miR-221 and miR-486. miR-30d exhibited no significant correlation between these levels. miR, microRNA.

patients with stage I-III NSCLC. In the present study, these miRNAs were detected in serum obtained from patients with advanced stage NSCLC. Subsequently, the PFS-associated serum miRNAs were detected in fresh tissue samples, in order to analyze the correlation between the expression of these miRNAs in serum and tissue.

It has been definitively demonstrated that the functions of genes are not isolated. Function-related genes may have 

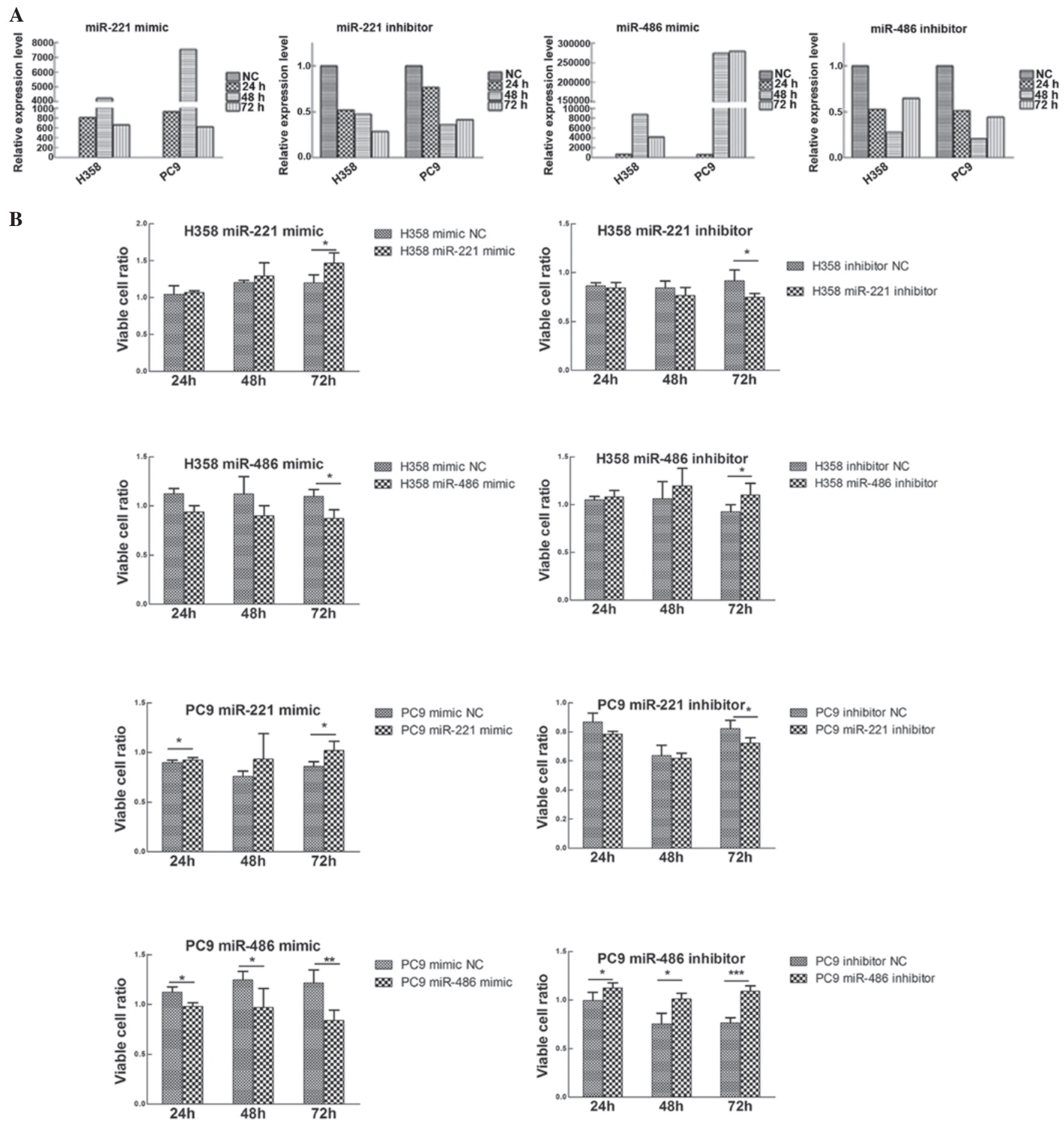

Figure 4. (A) Transient transfection efficiencies of miR-221 and miR-486 in H358 and PC9 cell lines. (B) Effects of miR-221 and miR-486 on cell proliferation. Transfection with miR-221 mimic or miR-486 inhibitor enhanced cell growth, whereas transfection with miR-221 inhibitor or miR-486 mimic decreased cell proliferation. Data are presented as the mean \pm standard deviation. ${ }^{*} \mathrm{P}<0.05,{ }^{* *} \mathrm{P}<0.01,{ }^{* * * *} \mathrm{P}<0.001$. miR, microRNA; NC, negative control.

similar expression profiles, and biological functions result from cooperation between genes. In addition, gene expression levels exhibit space-time specificity; therefore, a gene expression signature appears to be more suitable as a prognostic factor than a single biomarker.

In the serum miRNA analysis, a risk score formula was constructed using a Cox regression analysis and its predictive function was validated using cross-validation methods. Therefore, the PFS-associated miRNA expression level was transformed into a calculable risk score, which may have clinical application value. Repeated validation and distensible specimen detection are the key steps during biomarker identification. In the present analysis, an elementary validation was performed to establish a miRNA signature as a prognostic factor.

From the risk score formula, it was revealed that miR-1 and miR-486 exerted protective effects, whereas miR-30d and miR-221 were risk factors. miR-1 has previously been 
A
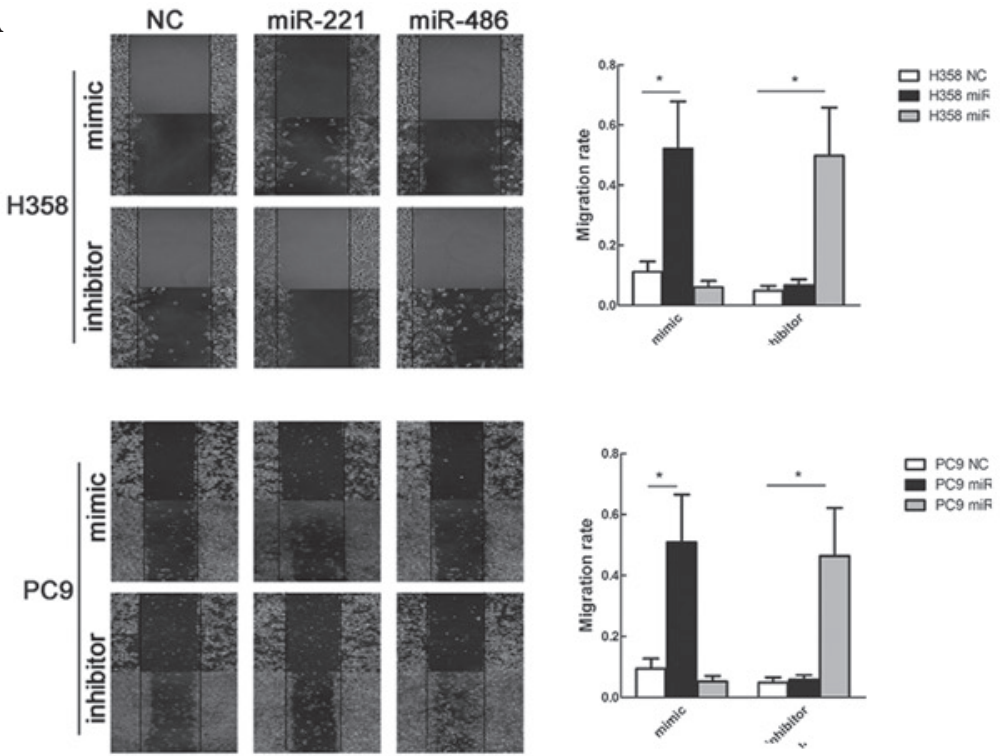

B
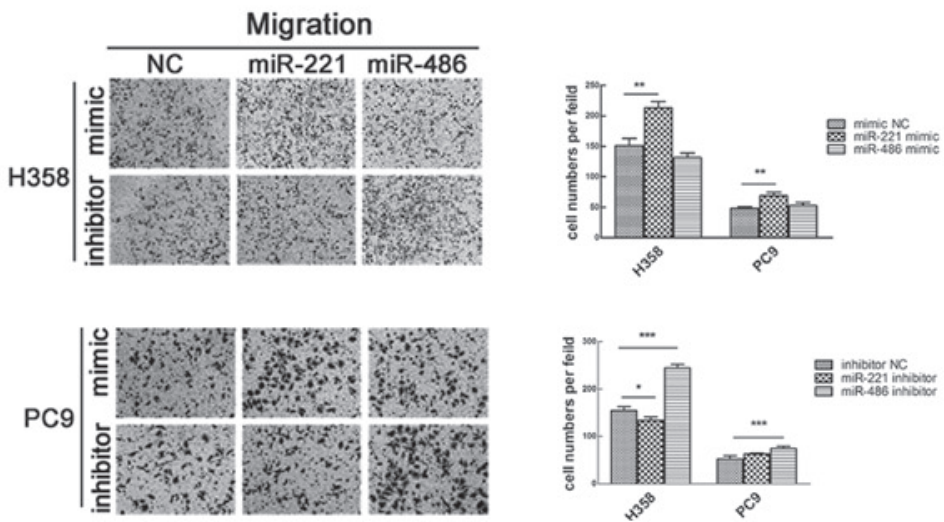

C
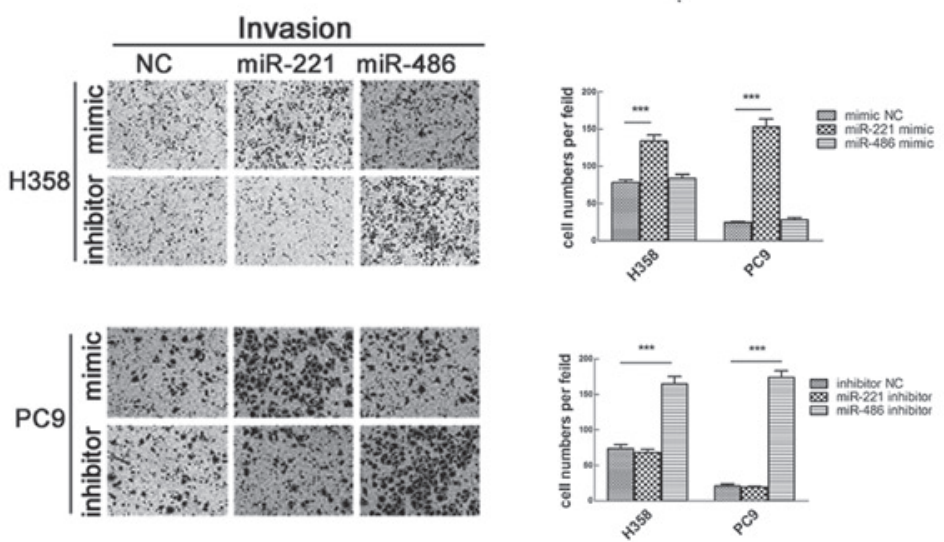

Figure 5. Upregulation of miR-221 or downregulation of miR-486 promotes cell migration and invasion. (A) Wound healing assay and (B) Transwell migration assay were used to measure cell migratory capacity. (C) Transwell invasion assay was used to measure cell invasive capacity. Magnification, x200. Data are presented as the mean \pm standard deviation. ${ }^{*} \mathrm{P}<0.05,{ }^{* *} \mathrm{P}<0.01,{ }^{* * * *} \mathrm{P}<0.001$. miR, microRNA; NC, negative control.

reported to act as a tumor suppressor by reducing migration and invasion, thus inhibiting growth in NSCLC (27) and head and neck squamous cell carcinoma (28). In addition, miR-486 is downregulated in the plasma and tissues of patients with NSCLC (29). A similar function for miR-486 has been reported in gastric carcinoma (30). The expression levels of miR-30d have been reported to be dysregulated in chronic lymphocytic leukemia (31) and hepatocellular carcinoma (HCC). According to a study by Yao et al (32), the increased expression levels of miR-30d enhanced cell migration and invasion in HCC. Furthermore, Li et al (33) reported that miR-30d overexpression significantly increased cell growth, thus acting as an oncomir. Regarded as a novel family of oncogenes, the overexpression of miR-221 may contribute to the oncogenesis and progression of prostate carcinoma $(34,35)$, and its overexpression is associated with tumor multifocality and reduced time to recurrence after surgery in HCC (36). 
In the aforementioned studies regarding early stage NSCLC specimens, miR-137, miR-182 and miR-372 tissue levels, but not serum levels, were reported to be associated with prognosis; and the same phenomenon was observed during serum detection in the present study. Therefore, it may be hypothesized that there are some differences in miRNA secretion. Since the majority of circulating miRNAs are released by cells, the authors of the present study are convinced that there is a connection between tissue expression and circulating miRNAs. There are three hypotheses regarding the release of miRNAs into the circulation: They may be released directly, packed into microparticles, or packed into exosomes (37). Indeed, the majority of previous studies have demonstrated the same trend of differences between circulating and tissue miRNAs. However, a different trend has also been observed. Wulfken et al (38) reported that only 36 of 109 high-level serum miRNAs were upregulated in tissues. Furthermore, Pigati et al (39) demonstrated that only $66 \%$ of extracellular miRNAs closely reflected cellular miRNAs, according to a miRNA microarray analysis. miR-544 expression was downregulated in serum but showed only a weak positive correlation with tissue expression (40). In the present study, miR-221 and miR-486 exhibited a significant correlation between serum and tissue levels. Conversely, miR-1 was detected as a risk factor in serum, but not in tissues. The correlation between serum and tissue miRNAs supports the hypothesis that circulating miRNAs can serve as a monitor for malignant lesions. Notably, because of the simplicity and reproducibility of obtaining blood samples, noninvasive, easily testable serum miRNAs may serve as a more promising biomarker for lung cancer prognosis.

Through the correlation analysis, the present study demonstrated that two miRNAs were relevant in both the cell environment and the non-cell environment. This finding provided the theoretical foundation for an in vitro study. In relation to PFS, which represents short-term survival, the proliferative, migratory and invasive capacities were studied in cell lines. It was observed that miR-221 was identified as an oncogenic risk factor, whereas miR-486 exerted protective effects against cancer cell proliferation, migration and invasion.

In conclusion, the present study identified a four-miRNA signature that independently contributed to PFS in patients with advanced NSCLC. The serum expression levels of miR-221 and miR-486 were positively correlated with those in tissue. Furthermore, the roles of miR-221 and miR-486 were verified in vitro.

\section{Acknowledgements}

The present study was funded by the National Natural Science Foundation of China (grant no. 81101690) and the major program of Hubei Provincial Health Department (grant no. JX6A02).

\section{References}

1. Siegel R, Naishadham D and Jemal A: Cancer statistics, 2013. CA Cancer J Clin 63: 11-30, 2013.

2. Ettinger DS, Akerley W, Borghaei H, Chang AC, Cheney RT, Chirieac LR, D'Amico TA, Demmy TL, Govindan R, Grannis FW Jr, et al; National comprehensive cancer network: Non-small cell lung cancer, version 2.2013. J Natl Compr Canc Netw 11: 645-653, 2013.
3. Jemal A, Center MM, DeSantis C and Ward EM: Global patterns of cancer incidence and mortality rates and trends. Cancer Epidemiol Biomarkers Prev 19: 1893-1907, 2010.

4. Kim ES, Herbst RS, Wistuba II, Lee JJ, Blumenschein GR Jr, Tsao A, Stewart DJ, Hicks ME, Erasmus J Jr, Gupta S, et al: The BATTLE trial: Personalizing therapy for lung cancer. Cancer Discov 1: 44-53, 2011.

5. Endoh H, Tomida S, Yatabe Y, Konishi H, Osada H, Tajima K Kuwano H, Takahashi T and Mitsudomi T: Prognostic model of pulmonary adenocarcinoma by expression profiling of eight genes as determined by quantitative real-time reverse transcriptase polymerase chain reaction. J Clin Oncol 22: 811-819, 2004

6. Yanaihara N, Caplen N, Bowman E, Seike M, Kumamoto K, Yi M, Stephens RM, Okamoto A, Yokota J, Tanaka T, et al: Unique microRNA molecular profiles in lung cancer diagnosis and prognosis. Cancer Cell 9: 189-198, 2006.

7. Director's Challenge Consortium for the Molecular Classification of Lung Adenocarcinoma, Shedden K, Taylor JM, Enkemann SA, Tsao MS, Yeatman TJ, Gerald WL, Eschrich S, Jurisica I, Giordano TJ, et al: Gene expression-based survival prediction in lung adenocarcinoma: A multi-site, blinded validation study. Nat Med 14: 822-827, 2008.

8. Morin P Jr: MiRNAs in cancer: Non-coding RNAs as appealing biomarkers for malignancy. Cancer Biomark 11: 227-228, 2012.

9. Steer CJ and Subramanian S: Circulating microRNAs as biomarkers: A new frontier in diagnostics. Liver Transpl 18: 265-269, 2012.

10. Calin GA and Croce CM: MicroRNA-cancer connection: The beginning of a new tale. Cancer Res 66: 7390-7394, 2006.

11. Kleivi Sahlberg K, Bottai G, Naume B, Burwinkel B, Calin GA, Børresen-Dale AL and Santarpia L: A serum microRNA signature predicts tumor relapse and survival in triple-negative breast cancer patients. Clin Cancer Res 21: 1207-1214, 2015

12. Liu N, Chen NY, Cui RX, Li WF, Li Y, Wei RR, Zhang MY, Sun Y, Huang BJ, Chen M, et al: Prognostic value of a microRNA signature in nasopharyngeal carcinoma: A microRNA expression analysis. Lancet Oncol 13: 633-641, 2012.

13. Hur K, Toiyama Y, Schetter AJ, Okugawa Y, Harris CC, Boland CR and Goel A: Identification of a metastasis-specific MicroRNA signature in human colorectal cancer. J Natl Cancer Inst 107: dju492, 2015.

14. Yu SL, Chen HY, Chang GC, Chen CY, Chen HW, Singh S, Cheng CL, Yu CJ, Lee YC, Chen HS, et al: MicroRNA signature predicts survival and relapse in lung cancer. Cancer Cell 13: 48-57, 2008.

15. Hu Z, Chen X, Zhao Y, Tian T, Jin G, Shu Y, Chen Y, Xu L, Zen $\mathrm{K}$, Zhang $\mathrm{C}$ and Shen $\mathrm{H}$ : Serum microRNA signatures identified in a genome-wide serum microRNA expression profiling predict survival of non-small-cell lung cancer. J Clin Oncol 28: 1721-1726, 2010.

16. Travis WD: Pathology of lung cancer. Clin Chest Med 23: 65-81, 2002.

17. Eisenhauer EA, Therasse P, Bogaerts J, Schwartz LH, Sargent D, Ford R, Dancey J, Arbuck S, Gwyther S, Mooney M, et al: New response evaluation criteria in solid tumours: Revised RECIST guideline (version 1.1). Eur J Cancer 45: 228-247, 2009.

18. Kroh EM, Parkin RK, Mitchell PS and Tewari M: Analysis of circulating microRNA biomarkers in plasma and serum using quantitative reverse transcription-PCR (qRT-PCR). Methods 50: 298-301, 2010.

19. Mahn R, Heukamp LC, Rogenhofer S, von Ruecker A, Müller SC and Ellinger J: Circulating microRNAs (miRNA) in serum of patients with prostate cancer. Urology 77: 1265. e9-e16, 2011.

20. Livak KJ and Schmittgen TD: Analysis of relative gene expression data using real-time quantitative PCR and the 2(-Delta Delta C(T)) Method. Methods 25: 402-408, 2001.

21. Chim SS, Shing TK, Hung EC, Leung TY, Lau TK, Chiu RW and Lo YM: Detection and characterization of placental microRNAs in maternal plasma. Clin Chem 54: 482-490, 2008.

22. Chen X, Ba Y, Ma L, Cai X, Yin Y, Wang K, Guo J, Zhang Y, Chen J, Guo X, et al: Characterization of microR NAs in serum: A novel class of biomarkers for diagnosis of cancer and other diseases. Cell Res 18: 997-1006, 2008.

23. Mitchell PS, Parkin RK, Kroh EM, Fritz BR, Wyman SK, Pogosova-Agadjanyan EL, Peterson A, Noteboom J, O'Briant KC, Allen A, et al: Circulating microRNAs as stable blood-based markers for cancer detection. Proc Natl Acad Sci USA 105: 10513-10518, 2008. 
24. Gilad S, Meiri E, Yogev Y, Benjamin S, Lebanony D, Yerushalmi N, Benjamin $\mathrm{H}$, Kushnir M, Cholakh $\mathrm{H}$, Melamed N, et al: Serum microRNAs are promising novel biomarkers. PloS One 3: e3148, 2008.

25. Lu Y, Govindan R, Wang L, Liu PY, Goodgame B, Wen W, Sezhiyan A, Pfeifer J, Li YF, Hua X, et al: MicroRNA profiling and prediction of recurrence/relapse-free survival in stage I lung cancer. Carcinogenesis 33: 1046-1054, 2012.

26. Liu R, Chen X, Du Y, Yao W, Shen L, Wang C, Hu Z, Zhuang R, Ning G, Zhang C, et al: Serum microRNA expression profile as a biomarker in the diagnosis and prognosis of pancreatic cancer. Clin Chem 58: 610-618, 2012.

27. Nasser MW, Datta J, Nuovo G, Kutay H, Motiwala T, Majumder S, Wang B, Suster S, Jacob ST and Ghoshal K: Down-regulation of micro-RNA-1 (miR-1) in lung cancer. Suppression of tumorigenic property of lung cancer cells and their sensitization to doxorubicin-induced apoptosis by miR-1. J Biol Chem 283: 33394-33405, 2008.

28. Nohata N, Sone Y,Hanazawa T, Fuse M, Kikkawa N, Yoshino H Chiyomaru T, Kawakami K, Enokida H, Nakagawa M, et al: MiR-1 as a tumor suppressive microRNA targeting TAGLN2 in head and neck squamous cell carcinoma. Oncotarget 2: 29-42, 2011.

29. Boeri M, Verri C, Conte D, Roz L, Modena P, Facchinetti F, Calabrò E, Croce CM, Pastorino U and Sozzi G: MicroRNA signatures in tissues and plasma predict development and prognosis of computed tomography detected lung cancer. Proc Natl Acad Sci USA 108: 3713-3718, 2011.

30. Oh HK, Tan AL, Das K, Ooi CH, Deng NT, Tan IB, Beillard E, Lee J, Ramnarayanan K, Rha SY, et al: Genomic loss of miR-486 regulates tumor progression and the OLFM4 antiapoptotic factor in gastric cancer. Clin Cancer Res 17: 2657-2667, 2011.

31. Marton S, Garcia MR, Robello C, Persson H, Trajtenberg F, Pritsch O, Rovira C, Naya H, Dighiero G and Cayota A: Smal RNAs analysis in CLL reveals a deregulation of miRNA expression and novel miRNA candidates of putative relevance in CLL pathogenesis. Leukemia 22: 330-338, 2008
32. Yao J, Liang L, Huang S, Ding J, Tan N, Zhao Y, Yan M, Ge C, Zhang Z, Chen T, et al: MicroRNA-30d promotes tumor invasion and metastasis by targeting Galphai2 in hepatocellular carcinoma. Hepatology 51: 846-856, 2010.

33. Li N, Kaur S, Greshock J, Lassus H, Zhong X, Wang Y, Leminen A, Shao Z, Hu X, Liang S, et al: A combined array-based comparative genomic hybridization and functional library screening approach identifies mir-30d as an oncomir in cancer. Cancer Res 72: 154-164, 2012.

34. Zheng C, Yinghao S and Li J: MiR-221 expression affects invasion potential of human prostate carcinoma cell lines by targeting DVL2. Med Oncol 29: 815-822, 2012.

35. Galardi S, Mercatelli N, Giorda E, Massalini S, Frajese GV, Ciafrè SA and Farace MG: MiR-221 and miR-222 expression affects the proliferation potential of human prostate carcinoma cell lines by targeting p27Kip1. J Biol Chem 282: 23716-23724, 2007.

36. Gramantieri L, Fornari F, Ferracin M, Veronese A, Sabbioni S, Calin GA, Grazi GL, Croce CM, Bolondi L and Negrini M: MicroRNA-221 targets Bmf in hepatocellular carcinoma and correlates with tumor multifocality. Clin Cancer Res 15: 5073-5081, 2009.

37. Zen K and Zhang CY: Circulating microRNAs: A novel class of biomarkers to diagnose and monitor human cancers. Med Res Rev 32: 326-348, 2012.

38. Wulfken LM, Moritz R, Ohlmann C, Holdenrieder S, Jung V, Becker F, Herrmann E, Walgenbach-Brünagel G, von Ruecker A, Müller SC and Ellinger J: MicroRNAs in renal cell carcinoma: Diagnostic implications of serum miR-1233 levels. PLoS One 6: e25787, 2011

39. Pigati L, Yaddanapudi SC, Iyengar R, Kim DJ, Hearn SA, Danforth D, Hastings ML and Duelli DM: Selective release of microRNA species from normal and malignant mammary epithelial cells. PloS One 5: e13515, 2010.

40. Ma R, Zhang G, Wang $\mathrm{H}$, Lv $\mathrm{H}$, Fang $\mathrm{F}$ and Kang $\mathrm{X}$ : Downregulation of miR-544 in tissue, but not in serum, is a novel biomarker of malignant transformation in glioma. Oncol Lett 4: $1321-1324,2012$ 